\title{
Atrial Flutter by ECG Finding
}

National Cancer Institute

\section{Source}

National Cancer Institute. Atrial Flutter by ECG Finding. NCI Thesaurus. Code C111094.

An electrocardiographic finding of an org anized, regular atrial rhythm with atrial rate of 240-340 beats per minute. Multiple $\mathrm{P}$ waves typically appear in the inferior leads in a saw tooth like pattern between the QRS complexes. (CDISC) 